Chronic Obstructive Pulmonary Diseases: Journal of the COPD Foundation

\title{
Original Research \\ Evaluation and Documentation of Supplemental Oxygen Requirements is Rarely Performed in Patients Hospitalized With COPD
}

Farhan Zaidi, MD ${ }^{1,2}$ Ryan S. Lee, $\mathrm{MD}^{1}$ Bartosz A. Buchcic, $\mathrm{MD}^{1,2}$ Nina E. Bracken, APN ${ }^{1,2,3}$

H. Ari Jaffe, MD ${ }^{1,2}$ Min Joo, MD, MPH ${ }^{1,2}$ Valentin Prieto-Centurion, MD ${ }^{1,2}$ Ai-Yui Tan, MD ${ }^{1,2,3}$ Jerry A. Krishnan, $\mathrm{MD}, \mathrm{PhD}^{1,2,3}$

\begin{abstract}
Rationale: Patients hospitalized with chronic obstructive pulmonary disease (COPD) who require supplemental oxygen $\left(\mathrm{O}_{2}\right)$ are at increased risk of hospital readmissions. There is a paucity of information regarding quality of evaluation and documentation regarding the need for supplemental $\mathrm{O}_{2}$ in this population.

Objective: To determine the extent to which evaluation and documentation regarding the need for supplemental $\mathrm{O}_{2}$ occurs prior to hospital discharge in patients with COPD.

Methods: We conducted a two-center retrospective cohort study of hospitalized adults with a physician diagnosis of COPD. We reviewed electronic health records to ascertain whether patients underwent evaluation beyond rest oximetry documenting hypoxemia and if there was adequate documentation of supplemental $\mathrm{O}_{2}$ requirements prior to discharge.

Results: Of 526 patients hospitalized with a primary or secondary discharge diagnosis of COPD, 335 patients (mean age 69 years, $78 \%$ with diagnosis of COPD exacerbation) met eligibility criteria. Overall, 1 in 5 (22\%, 73/335) hospitalized patients with COPD had an evaluation beyond rest oximetry for supplemental $\mathrm{O}_{2}$ requirements during admission. Adequate documentation of supplemental $\mathrm{O}_{2}$ requirements occurred in even fewer patients $(16 \%, 54 / 335)$. Both evaluation ( $26 \%$ versus $5 \%, p=0.002)$ and documentation ( $19 \%$ versus $4 \%$, $p=0.001$ ) of supplemental $\mathrm{O}_{2}$ requirements were more common in patients hospitalized for a COPD exacerbation compared to those hospitalized with COPD but without an exacerbation.

Conclusions: Evaluation and documentation of supplemental $\mathrm{O}_{2}$ requirements beyond rest oximetry occur infrequently in patients hospitalized with COPD.
\end{abstract}

\footnotetext{
Abbreviations: chronic obstructive pulmonary disease, COPD; oxygen, $\mathbf{O}_{\mathbf{2}}$; Centers for Medicare and Medicaid Services, CMS; Documentation and evaluation of Oxygen Requirements In COPD study, DORIC; electronic health records, EHR; forced expiratory volume in 1 second, FEV $\mathbf{1}$; forced vital capacity, FVC; Global initiative for chronic Obstructive Lung Disease, GOLD; pulse oximetry, SpO 2 ; LongTerm Oxygen Treatment Trial, LOTT; standard deviation, SD; against medical advice, AMA

Funding Support: Dr. Zaidi is supported by a National Institutes of Health institutional training grant (T32 HL082547).

Date of Acceptance: July 20, 2017

Citation: Zaidi F, Lee RS, Buchcic BA, et al. Evaluation and documentation of supplemental oxygen requirements is rarely performed in patients hospitalized with COPD. Chronic Obstr Pulm Dis. 2017;4(4):287-296. doi: https://doi.org/10.15326/jcopdf.4.4.2017.0148
}

1 Division of Pulmonary, Critical Care, Sleep and Allergy, Department of Medicine, University of Illinois at Chicago 3 Population Health Sciences Program, University of Illinois
Hospital \& Health Sciences System, Chicago

2 Jesse Brown Veterans Administration Medical Center, Chicago,

Illinois 


\section{Address correspondence to:}

Farhan Zaidi, MD

University of Illinois at Chicago

Mile Square, 3rd floor, Room 3041

1220 S Wood St. (M/C 619)

Chicago, IL 60608

Phone: (312) 413-1960

Email: fzaidi1@uic.edu

\section{Keywords:}

supplemental oxygen; chronic obstructive pulmonary disease; COPD; quality of care; hospitalization; readmission

\section{Introduction}

Chronic obstructive pulmonary disease (COPD) is a common respiratory disorder that affects 15 million individuals and is the third leading cause of death in the United States. ${ }^{1,2,3}$ Despite optimal medical therapy, patients with COPD have episodic worsening of respiratory symptoms (exacerbations). In the United States alone, COPD exacerbations account for about 750,000 hospitalizations each year. ${ }^{4,5}$ Among patients who are hospitalized with a COPD exacerbation and who survive to hospital discharge, the hospital-specific 30day risk of death and 30-day risk of readmission varies greatly (6\% to $13 \%$ and $19 \%$ to $26 \%$, respectively). ${ }^{6,7}$ These observations led to a decision by the U.S. Centers for Medicare and Medicaid Services (CMS) to include COPD in its efforts to improve the quality and outcomes of care in hospitalized patients. ${ }^{8}$

In patients with COPD associated with severe resting room air hypoxemia, appropriate use of supplemental oxygen $\left(\mathrm{O}_{2}\right)$ saves lives ( 1 life saved for every 4 patients treated over 5 years). ${ }^{9,10}$ Patients with COPD who are prescribed supplemental $\mathrm{O}_{2}$ for use after hospital discharge have an increased risk of hospital readmission. ${ }^{11,12}$ As patients with more severe COPD are more likely to be prescribed supplemental $\mathrm{O}_{2}$, the association between supplemental $\mathrm{O}_{2}$ and readmission may, in part, represent confounding by disease severity. Inappropriate use of supplemental $\mathrm{O}_{2}$ after hospital discharge could impact patient safety and contribute to poor outcomes in this population. ${ }^{13}$

CMS requires specific documentation to support a prescription for supplemental $\mathrm{O}_{2}$, which includes $\mathrm{O}_{2}$ flow rate at rest, with activity, or sleep, as well as the type of $\mathrm{O}_{2}$ delivery system. ${ }^{14}$ Inadequate documentation can lead to delays in initiation of $\mathrm{O}_{2}$ therapy, as well as denial of insurance coverage with the patient becoming responsible for the costs of supplemental $\mathrm{O}_{2}$ therapy.
Inadequate documentation could also lead to confusion about the appropriate use of $\mathrm{O}_{2}$ among patients and their caregivers leading to underuse or overuse of supplemental $\mathrm{O}_{2}{ }^{15}$

Despite the importance of documentation to support a clinical indication for supplemental $\mathrm{O}_{2}$ in patients hospitalized with COPD, there is a surprising paucity of published information about the quality of evaluation and documentation regarding the need for supplemental $\mathrm{O}_{2}$ in this population. Addressing this information gap could help to inform the need for hospital-based quality improvement programs devoted to oxygen prescriptions prior to hospital discharge as an additional strategy to enhance patient safety and to reduce avoidable readmissions in patients with COPD.

Therefore, the objective of the Documentation and evaluation of Oxygen Requirements In COPD (DORIC) study was to determine the extent to which evaluation and documentation regarding the need for supplemental $\mathrm{O}_{2}$ occurred prior to hospital discharge in patients with COPD. Secondary objectives of the DORIC study were to examine the extent to which evaluation and documentation occurred prior to discharge in patients hospitalized with COPD with and without an exacerbation, as well as in those prescribed and not prescribed supplemental $\mathrm{O}_{2}$ at home prior to the index hospitalization.

\section{Materials and Methods}

We conducted a retrospective cohort study of adults at 2 academic health care centers in Chicago, Illinois (a university-affiliated hospital and a Veterans Affairs medical center). The study received a waiver for the requirement of informed consent and institutional review board approval was obtained at both institutions (\#2015-0572; \#833934-1).

\section{Patient Selection and Baseline Characteristics}

The following screening criteria were used to identify hospitalizations that were subsequently assessed for eligibility:

(1) age $\geq 40$ years old;

(2) discharged from the hospital between January 1, 2013 and December 31, 2014 (study period); and (3) an International Classification of Diseases, Ninth Revision, Clinical Modification (ICD-9-CM) discharge diagnosis code used by the CMS to identify patients hospitalized with a COPD exacerbation: a) 
primary diagnosis of COPD (491.21, 491.22, 491.8, 491.9, 492.8, 493.20, 493.21, 493.22, and 496), or b) a primary diagnosis of respiratory failure (518.81, $518.82,518.84,799.1)$ with a secondary diagnosis of COPD exacerbation (491.21, 491.22, 493.21, 493.22). ${ }^{16}$

The electronic health records (EHRs) for hospitalizations that met screening criteria were reviewed by 2 clinicians (FZ or RSL) to identify hospitalizations with a physician documentation of COPD in the discharge summary (emphysema, chronic obstructive pulmonary disease, or COPD). Hospitalization records were deemed ineligible if: (1) the patient had a previous hospitalization during the study period (only the first hospitalization was eligible); or (2) the patient was transferred to another hospital, discharged to hospice, left against medical advice, or died prior to hospital discharge.

The following information was collected from the EHRs: date of birth, race, sex, physician diagnosis of a COPD exacerbation, and prescribed supplemental $\mathrm{O}_{2}$ at home prior to the index hospitalization. We also extracted information about the results of the most recent spirometry test results within a 2-year period prior to the index hospitalization. We selected this review window because we demonstrated in a previous study that spirometry test results may not be available in the EHR in a substantial proportion of patients even when reviewing a 2-year period prior to a hospitalization. ${ }^{17}$ Airflow obstruction was defined as a post-bronchodilator forced expiratory volume in 1 second $\left(F E V_{1}\right)$ to the forced vital capacity $(F V C)$ ratio of $<0.70$. We further characterized airflow obstruction as mild or moderate $\left(\mathrm{FEV}_{1}>50 \%\right)$, or as severe or very severe $\left(\mathrm{FEV}_{1}<50 \%\right)$ using the 2016 Global initiative for chronic Obstructive Lung Disease (GOLD) guidelines. $^{1}$

\section{Adequacy of Evaluation for Supplemental $\mathrm{O}_{2}$ Requirement}

We reviewed the physician admission history and physical, progress notes (documented by nurses, physicians, or respiratory therapists), pulmonary function laboratory test results, and the discharge summary for the index hospitalization to determine if patients underwent an evaluation of supplemental $\mathrm{O}_{2}$ requirements beyond rest oximetry. An adequate evaluation of supplemental $\mathrm{O}_{2}$ requirements was defined as a test (documentation of a 6-minute walk test, exercise desaturation study, or bedside evaluation by a clinician) performed to assess the oxygenation as determined by pulse oximetry $\left(\mathrm{SpO}_{2}\right)$ or arterial blood gas at rest and with activity within the 48hour period prior to hospital discharge. The 48hour window prior to hospital discharge was selected based on CMS requirements for documentation to support a prescription for supplemental $\mathrm{O}_{2}$ initiated in hospitalized patients. ${ }^{14}$

We defined an increase in $\mathrm{O}_{2}$ requirement as: (1) a new requirement in patients who were not on supplemental $\mathrm{O}_{2}$ prior to the index hospitalization; or (2) an increase in the flow of $\mathrm{O}_{2}$ at rest or with exercise. A decrease in $\mathrm{O}_{2}$ requirement was defined as: (1) no requirement in patients who were on supplemental $\mathrm{O}_{2}$ prior to the index hospitalization; or (2) a decrease in the flow of $\mathrm{O}_{2}$ at rest or with exercise.

\section{Adequacy of Documentation of Supplemental $\mathrm{O}_{2}$ Requirements}

For patients who were identified as needing supplemental $\mathrm{O}_{2}$, we reviewed the discharge summary and written instructions provided to patients at the time of the hospital discharge. Adequate documentation was defined as documentation of all the following information: the $\mathrm{O}_{2}$ flow at rest and with activity, and the type of $\mathrm{O}_{2}$ delivery device (e.g., nasal cannula). ${ }^{14}$ For example, "home $\mathrm{O}_{2}$ by nasal cannula, $2 \mathrm{~L} / \mathrm{min}$ at rest and $3 \mathrm{~L} / \mathrm{min}$ with exercise" was considered adequate documentation. "On home $\mathrm{O}_{2}$ as needed" was considered inadequate documentation. Review of data extracted from the EHR in the first 50 hospitalizations failed to identify a single instance of documentation of supplemental $\mathrm{O}_{2}$ requirements during sleep, so we did not include such documentation in the definition of "adequate documentation". Therefore, our results could be considered a "liberal" definition of adequate documentation.

\section{Statistical Analysis}

Descriptive statistics included the mean, standard deviation, frequency, and proportions, as appropriate. Chi-square tests were used to calculate differences in proportions. Two clinicians (FZ and BB) independently abstracted information about whether an evaluation for supplemental $\mathrm{O}_{2}$ requirement occurred (yes versus no) and whether there was adequate documentation of supplemental $\mathrm{O}_{2}$ requirements (yes versus no) in a 
$20 \%$ random sample of EHRs. Kappa statistics were computed to evaluate the inter-rater agreement of extracting this information from the EHRs. ${ }^{18}$ There was substantial inter-rater reliability for abstracting information about the evaluation (kappa=0.7) and documentation (kappa=0.8) of supplemental $\mathrm{O}_{2}$ requirements. A two-tailed $p$-value of less than 0.05 indicated a statistically significant difference. Analyses were performed using $\mathrm{R}$, version 3.3.0

\section{Results}

Of 526 hospitalizations, 335 met eligibility criteria (Figure 1). Patients were mostly men and African American (Table 1). Two-thirds of patients (65\%) had documentation of post-bronchodilator spirometry in the EHR, and within this group, about half had severe or very severe airflow obstruction. The majority (78\%) of patients had a physician documentation of a COPD exacerbation. Supplemental $\mathrm{O}_{2}$ use prior to hospital admission was nearly twice as likely in patients hospitalized with a COPD exacerbation versus patients hospitalized with COPD without an exacerbation (33\% versus $19 \%, p=0.02$ ).

\section{Adequacy of Evaluation of Supplemental $\mathrm{O}_{2}$ Requirements Within 48 Hours of Hospital Discharge}

Overall, about 1 in $5(22 \%, 73 / 335)$ patients hospitalized with COPD underwent an adequate evaluation for supplemental $\mathrm{O}_{2}$ requirement. Results were similar in the 2 hospitals that were included in the study (23\% versus $21 \%$ of patients had an evaluation, $p=0.58)$. Patients hospitalized with a COPD exacerbation were 5 times as likely to have an adequate evaluation for supplemental $\mathrm{O}_{2}$ compared to those hospitalized with COPD but without an exacerbation (26\% [69/262] versus 5\% [4/73], $p=0.002)$. However, an adequate evaluation for supplemental $\mathrm{O}_{2}$ requirements was not associated with whether or not patients were prescribed supplemental $\mathrm{O}_{2}$ prior to hospitalization (Figure 2).

In the subgroup of 20 patients hospitalized with a COPD exacerbation, prescribed supplemental $\mathrm{O}_{2}$ prior to hospitalization, and who underwent a re-evaluation of their $\mathrm{O}_{2}$ requirement, a roughly equal number of patients had an increase $(5 / 20,25 \%)$, decrease $(8 / 20$, $40 \%)$, or no change $(7 / 20,35 \%)$ in $\mathrm{O}_{2}$ requirements. In the subgroup of 49 patients hospitalized with a COPD exacerbation, who were not prescribed supplemental $\mathrm{O}_{2}$ prior to hospitalization, and who underwent an evaluation of their $\mathrm{O}_{2}$ requirement, 20/49 (41\%) were found to have a new $\mathrm{O}_{2}$ requirement. Thus, in the 69 patients hospitalized with a COPD exacerbation and who underwent an evaluation for supplemental $\mathrm{O}_{2}$ requirements, 33 (48\%) had either an increase, decrease, or new $\mathrm{O}_{2}$ requirement.

\section{Adequacy of Documentation of Supplemental $\mathrm{O}_{2}$ Requirements Within 48 Hours of Hospital Discharge}

Adequate documentation of supplemental $\mathrm{O}_{2}$ requirements at rest and with exertion, occurred in fewer than a fifth (16\%, 54/335) of all hospitalized patients with COPD and was 5 times as likely in patients hospitalized with a physician diagnosis of COPD exacerbation compared to those without an exacerbation (19\% versus $4 \%$, respectively, $p=0.001$ ). Adequate documentation for supplemental $\mathrm{O}_{2}$ requirements was more likely in patients who were on versus not on supplemental $\mathrm{O}_{2}$ prior to hospitalization (patients with a COPD exacerbation: $p=0.03$; patients without a COPD exacerbation: $\mathrm{p}=0.04$; Figure 3 ).

\section{Discussion}

In this two-center study of 335 patients hospitalized with COPD, the majority had gaps in the evaluation and documentation of oxygen prescriptions prior to discharge. Only 1 in 5 underwent an evaluation and fewer than 1 in 5 had adequate documentation of supplemental $\mathrm{O}_{2}$ requirements at rest and with activity prior to hospital discharge. Compared to patients hospitalized with COPD but without an exacerbation, patients hospitalized with a COPD exacerbation were 5 times as likely to have an adequate evaluation and 5 times as likely to have adequate documentation of supplemental $\mathrm{O}_{2}$ requirements prior to hospital discharge. Being prescribed supplemental $\mathrm{O}_{2}$ at home prior to the index hospitalization was not associated with a re-evaluation of supplemental $\mathrm{O}_{2}$ requirements, but was associated with an increased likelihood of having adequate documentation prior to discharge.

To our knowledge, this is the first study to report the evaluation and documentation of supplemental $\mathrm{O}_{2}$ requirements prior to discharge in patients hospitalized with COPD. ${ }^{1}$ The surprisingly poor performance on this aspect of COPD care linked to improving survival 


\section{Figure 1. COPD Patients Eligible and Ineligible for the DORIC Study}

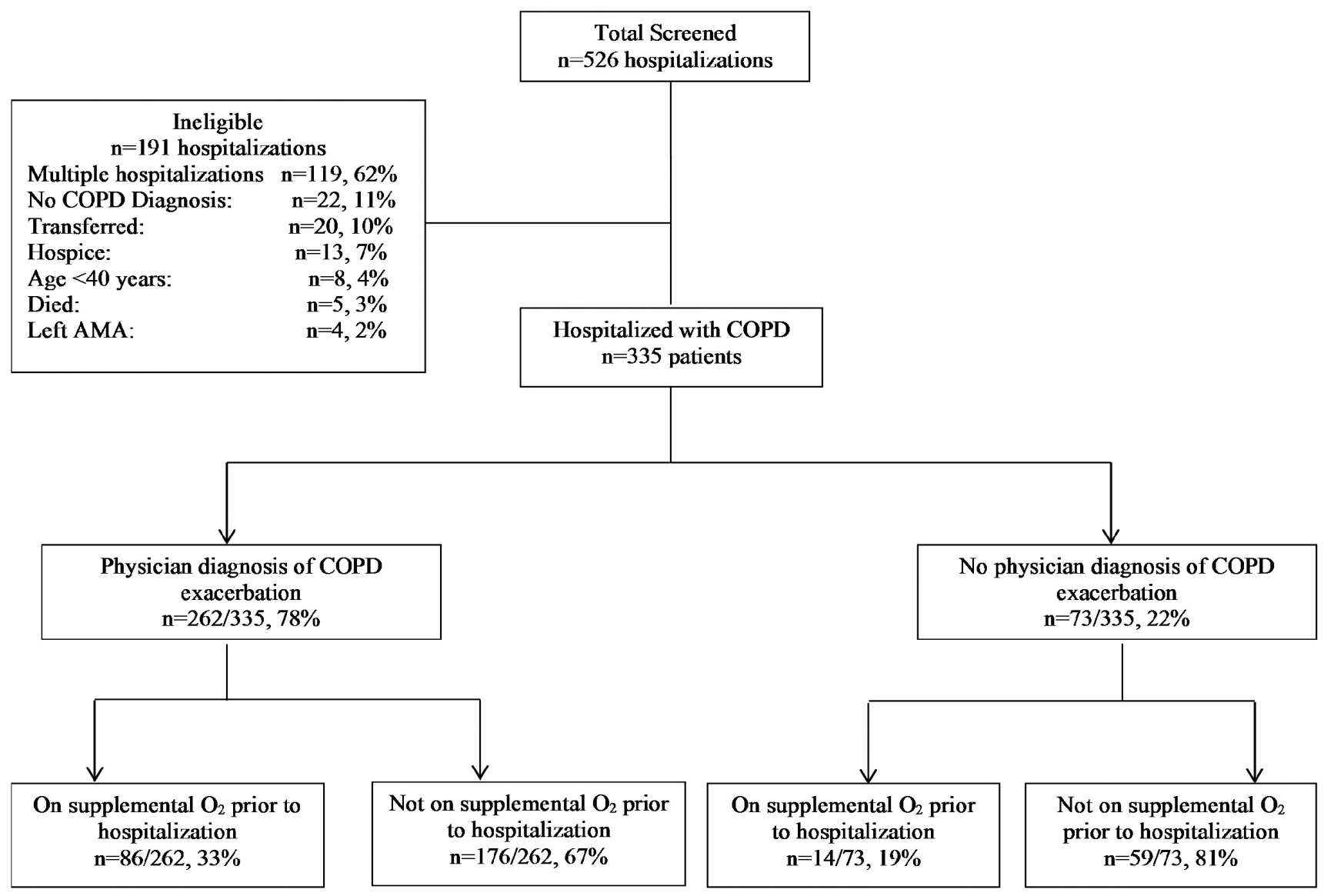

$\mathrm{O}_{2}$ evaluation in patients with COPD prior to hospital discharge stratified by whether or not they were hospitalized with physician documentation of a COPD exacerbation. Of 526 hospitalizations screened for eligibility, 335 (64\%) met eligibility criteria and 191 hospitalizations were ineligible. The most common reasons for being ineligible were repeat hospitalizations in the same individual (62\% of ineligible hospitalizations) and lack of physician documentation of a COPD exacerbation (11\%). Of the 335 eligible hospitalizations, $262(78 \%)$ had physician documentation of a COPD exacerbation. Patients hospitalized with a COPD exacerbation were more likely to be on supplemental $\mathrm{O}_{2}$ prior to hospitalization than patients with COPD hospitalized for other reasons $(33 \%$ versus $19 \%$, $p=0.02$ ).

AMA: against medical advice

is noteworthy. Our data were collected before the publication of the Long-Term Oxygen Treatment Trial (LOTT) study in patients with COPD, which did not find a beneficial effect of supplemental oxygen in patients with moderate desaturation at rest $\left(\mathrm{SpO}_{2} 89 \%\right.$ to $\left.93 \%\right)$ or with exercise-induced hypoxemia $\left(\mathrm{SpO}_{2}<90 \%\right.$ for $>10$ seconds, but without a $\mathrm{SpO}_{2}<80 \%$ for $>1$ minute during a 6-minute walk test). ${ }^{19}$ However, the LOTT study excluded patients who had a COPD exacerbation in the previous 30 days, so the applicability of our study among hospitalized patients to the LOTT study population is unclear. We also found that among patients hospitalized with a COPD exacerbation and who underwent an evaluation for supplemental $\mathrm{O}_{2}$ requirements, nearly half (48\%) had an increase, decrease, or new $\mathrm{O}_{2}$ requirement. While clinicians may have appropriately targeted patients who required a re-evaluation, it raises the question about whether patients who did not undergo an evaluation also would have had a change in their supplemental $\mathrm{O}_{2}$ prescription. The lack of adequate documentation about supplemental $\mathrm{O}_{2}$ requirements in over $80 \%$ of participants in our study suggests that most patients discharged to home on supplemental $\mathrm{O}_{2}$ also do not receive adequate safety-related instructions, such as avoiding smoking or being near an open flame while using $\mathrm{O}_{2}{ }^{20,21}$ These considerations highlight an important oportunity to improve care, 


\section{Table 1. Patient Characteristics}

\section{Patient Characteristic}

Age, years $( \pm \mathrm{SD})$

Male, $\mathrm{n}(\%)$

Race, $\mathrm{n}(\%)$

\begin{tabular}{l|r}
\hline African American & $226(67)$ \\
\hline White & $80(24)$ \\
\hline Other & $25(7)$ \\
\hline Asian & $2(1)$ \\
\hline American Indian or Alaskan Native & $2(1)$ \\
\hline
\end{tabular}

Spirometry, $\mathrm{n}(\%)^{1}$

No spirometry in the last 24 months

Spirometry results available

Normal spirometry

Mild to moderate airflow obstruction

Severe and very severe airflow obstruction

Diagnosis of COPD exacerbation at index hospitalization, $\mathrm{n}(\%)$

Prescribe supplemental $\mathrm{O}_{2}$ prior to index hospitalization, $\mathrm{n}(\%)$

${ }^{1}$ Spirometry performed within two years prior to index hospitalization. If more than one spirometry result was available, the latest one was used.

SD: standard deviation; GOLD: Global initiative for chronic Obstructive Lung Disease $(n=335)$

$68.7 \pm 10.8$

$231(69)$

$116(35)$

$219(65)$

$14(6)$

$83(39)$

$122(56)$

$262(78)$

$100(30)$ and potentially safety, in patients recently hospitalized with COPD. ${ }^{16,22}$ Our retrospective study did not evaluate potential reasons for omitting an evaluation or lack of documentation about supplemental $\mathrm{O}_{2}$. Additional studies are needed to evaluate the extent to which inadequate awareness, agreement, or ability to implement guidelines contributed to gaps in the quality of oxygen prescriptions in this high-risk population. ${ }^{23}$

There is increasing interest in medication reconciliation at times of transitions in care, such as during a discharge from the hospital to home. ${ }^{24}$ In this context, medication reconciliation refers to processes to avoid inadvertent omissions, duplications, or incorrect doses of medications by reviewing the patient's medication regimen (e.g., using self-report, prescription refills) with instructions provided to patients at the time of hospital discharge. ${ }^{25}$ A systematic review of clinical trials found that medication reconciliation reduced discrepancies, with a decrease in actual and potential adverse drug events. ${ }^{26}$ Anecdotal experience suggests that some clinicians include $\mathrm{O}_{2}$ prescriptions as part of the medication reconciliation process, however this practice is not universal and is not specifically recommended by the Agency for Healthcare Research and Quality's Medications at Transitions and Clinical Handoffs' Toolkit for Medication Reconciliation. ${ }^{27}$ CMS does not reimburse $\mathrm{O}_{2}$ as a medication but rather as durable medical equipment. ${ }^{14}$ This could explain why appropriate documentation of $\mathrm{O}_{2}$ prescriptions is not included in hospital-based efforts to develop and implement medication reconciliation processes.

This DORIC study has a number of strengths. First, our study addresses an important aspect of care in patients with COPD - the use of supplemental $\mathrm{O}_{2}$ - one of very few treatments that has been demonstrated to increase survival. ${ }^{9,10}$ Second, we included over 300 patients and observed similarly low performance at 2 institutions, suggesting that our findings may not be an isolated problem in the quality

of COPD care. Our study also has some important limitations. We assessed information in the EHR, and it is possible that evaluation and documentation of care was recorded elsewhere (e.g., notes by clinicians on paper forms submitted to durable medical equipment companies). Such information is required by durable medical equipment companies when requesting initiation of supplemental oxygen, but not when patients were previously on supplemental oxygen. In the 2 study hospitals, the EHR did not contain a scanned copy of forms submitted to durable medical equipment companies or other such documentation. It is our view that the EHR should contain information relevant to the care of patients, so that post-acute care clinicians, patients, and their caregivers have the information they need to provide appropriate care. Also, our study focused on 2 hospitals and it is not known if results are generalizable to other settings. Additional studies involving different regions, urban/ rural settings, for profit versus not for profit hospitals, teaching versus nonteaching hospitals, hospital versus ambulatory settings are needed to compare 


\section{Figure 2. Oxygen Evaluation in COPD Patients Prior to Hospital Discharge}

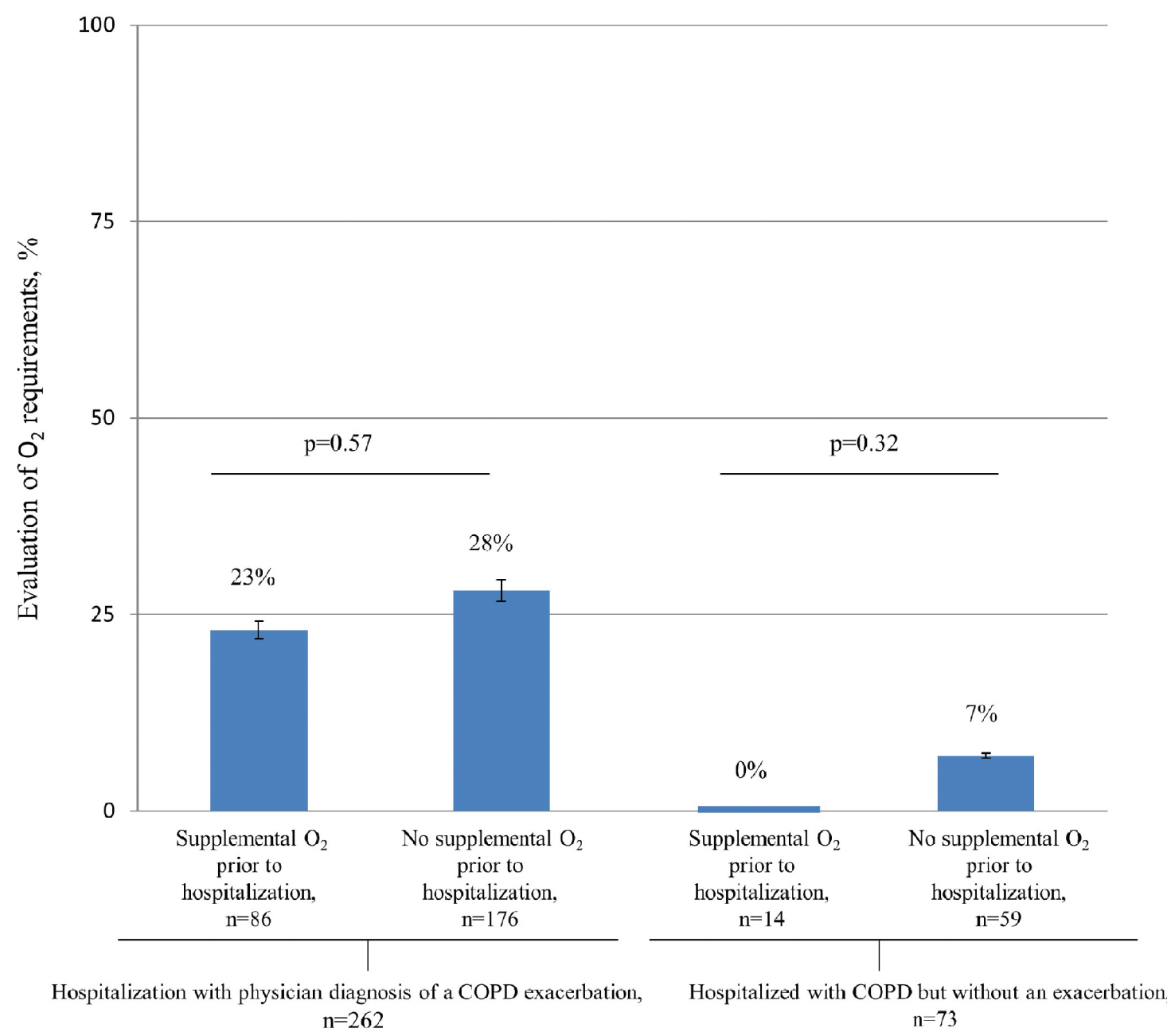

Only $22 \%(73 / 335)$ of patients had an evaluation for supplemental $\mathrm{O}_{2}$ requirements within 48 hours prior to discharge. Patients hospitalized with a COPD exacerbation were 5 times as likely to have an evaluation for supplemental $\mathrm{O}_{2}$ compared to those hospitalized with COPD without an exacerbation $(26 \%$ [69/262] versus $5 \%$ [4/73], $p=0.002)$. Whether or not patients were prescribed supplemental $\mathrm{O}_{2}$ prior to hospitalization was not associated with an evaluation for supplemental $\mathrm{O}_{2}$ requirement.

performance across various care settings. We also did not assess the barriers and facilitators of evaluation and documentation of supplemental $\mathrm{O}_{2}$ requirements; additional studies devoted to this question are needed, as well as studies to identify best practices for improving the quality of care regarding the evaluation and documentation of supplemental $\mathrm{O}_{2}$ requirements.

In conclusion, our study suggests that adequate evaluation and documentation of supplemental $\mathrm{O}_{2}$ requirements is rarely performed in patients hospitalized with COPD. Further research is required to determine if our findings generalize to other settings and to assess the effectiveness of strategies that promote an evaluation and documentation of supplemental $\mathrm{O}_{2}$ requirements at rest and with activity prior to hospital discharge on patient safety, including avoidable readmissions.

\section{Acknowledgements}

The authors thank all study patients and the staff of the Breathe Chicago Center ${ }^{\circledast}$ at the University of Illinois at Chicago for their assistance in conducting this study. Author contributions: All authors had access to the data and take responsibility for the integrity of the data and the accuracy of the data analysis. F.Z. contributed to the study conception, hypothesis delineation, data analysis and interpretation, writing and revision of the manuscript. J.A.K. contributed to the study 


\section{Figure 3. Documentation of Oxygen Requirements}

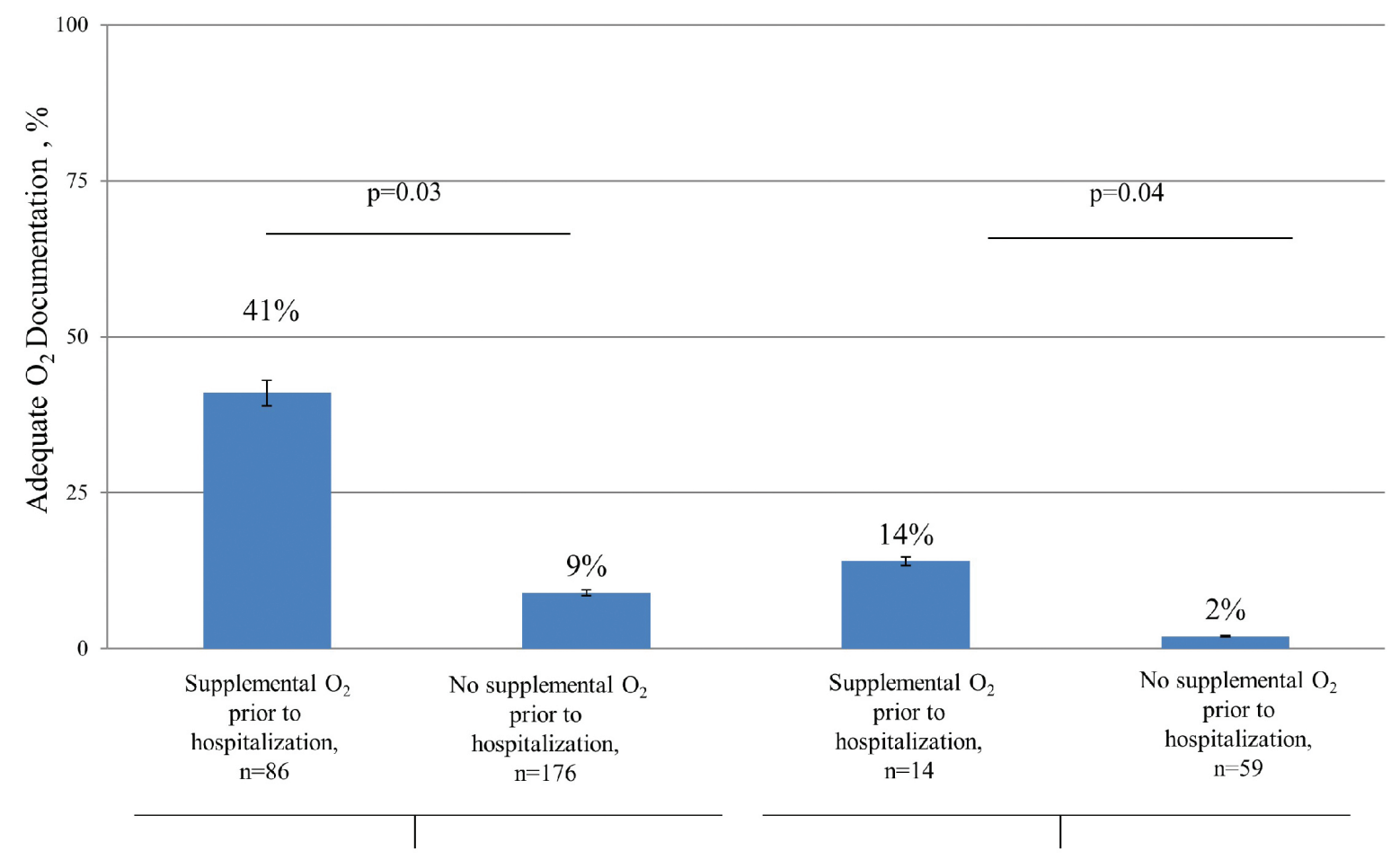

Physician diagnosis of a COPD exacerbation, No physician diagnosis of a COPD exacerbation, $n=262$

$n=73$

Only $16 \%$ (54 of 335) of patients hospitalized with COPD had adequate documentation of $\mathrm{O}_{2}$ requirements at rest and with activity 48 hours prior to hospital discharge. Adequate documentation was more common in patients hospitalized with a physician diagnosis of a COPD exacerbation than in patients hospitalized with COPD but without an exacerbation (19\% [51/262] versus 4\% [3/73], $p=0.001)$. A minority of patients with COPD had an adequate documentation of their $\mathrm{O}_{2}$ requirements at discharge, whether or not they were hospitalized with a COPD exacerbation. Patients on supplemental $\mathrm{O}_{2}$ prior to hospitalization (versus not prior to hospitalization) were more likely to have adequate documentation whether or not they were hospitalized with a COPD exacerbation.

conception, hypothesis delineation, data acquisition, analysis and interpretation, writing and revision of the manuscript. R.S. L., V.P.C., and B.A.B. contributed to the acquisition and interpretation of the data and revision of the manuscript. A.T, H.A.J, N.E.B., and M.J. contributed to the interpretation, writing, and revision of the manuscript. The views expressed in this article are those of the authors and do not necessarily reflect the position or policy of the Department of Veterans
Affairs, the U.S. government, or the National Institutes of Health.

\section{Declaration of Interests}

None of the authors have any real of apparent conflicts of interest including financial and consulting relationships. 


\section{References}

1. Global Initiative for Chronic Obstructive Lung Disease (GOLD). GOLD website. http://goldcopd.org/global-strategy-diagnosismanagement-prevention-copd-2016/ Published 2016. Accessed October 24, 2016.

2. Centers for Disease Control and Prevention. Chronic obstructive pulmonary disease among adults - United States, 2011. MMWR Morb Mortal Wkly Rep. 2012; 61(46): 938-943.

3. Mini-o AM, Murphy SL, Xu JQ, Kochanek KD. Deaths: Final data for 2008. Nat Vital Stat Rep. 2011.59(10): 1-127.

4. Xu J, Murphy Sl, Kockanek MS, Bastian B. Deaths: Final data for 2013. Nat Vital Stat Rep. 2016; 64(2):1-119.

5. National Heart, Lung, and Blood Institute (NHLBI). 2012 NHLBI Morbidity and Mortality Chart Book. http://www.nhlbi. nih.gov/research/reports/2012-mortality-chart-book. Published February 2012. Updated May 2013. Accessed October 24, 2016.

6. Sjoding MW, Cooke CR. Readmission penalties for chronic obstructive pulmonary disease will further stress hospitals caring for vulnerable patient populations. Am J Resp Crit Care Med. 2014; 190(90):1072-1074.

7. Lindenauer PK, Grosso LM, Wang C, et al. Development, validation, and results of a risk-standardized measure of hospital 30-day mortality for patients with exacerbation of chronic obstructive pulmonary disease. J Hosp Med. 2013;8(8):428-435. doi: https://doi.org/10.1002/jhm.2066

8. U.S. Congress, House Committee on Ways and Means, Committee on Energy and Commerce, Committee on Education and Labor. Compilation of Patient Protection and Affordable Care Act: As amended through 1 November 2010, including Patient Protection and Affordable Care Act health-related portions of the Health Care and Education Reconciliation Act of 2010. U.S. House of Representatives website. http://housedocs. house.gov/energycommerce/ppacacon.pdf Published 2010. Accessed October 2016.

9. Nocturnal Oxygen Therapy Trial Group. Continuous or nocturnal oxygen therapy in hypoxemic chronic obstructive lung disease: a clinical trial. Ann Intern Med.1980; 93(3):391-398. doi: https://doi.org/10.7326/0003-4819-93-3-391

10. Long term domiciliary oxygen therapy in chronic hypoxic cor pulmonale complicating chronic bronchitis and emphysema. Report of the Medical Research Council Working Party. Lancet. 1981; 1:681-686.

11. Croxton TL, Bailey WC. Long-term oxygen treatment in chronic obstructive pulmonary disease: recommendations for future research: an NHLBI workshop report. Am J Respir Crit Care Med. 2006; 174(4):373-37.

doi: https://doi.org/10.1164/rccm.200507-1161WS
12. Garcia-Aymerich J, Farrero E, Felez MA, Izquierdo J, Marrades RM, Anto JM. Risk factors of readmission to hospital for a COPD exacerbation: a prospective study. Thorax. 2013; 58(2): 100-105. doi: https://doi.org/10.1136/thorax.58.2.100

13. Katsenos S, Constantopoulos SH. Long-term oxygen therapy in COPD: Factors affecting and ways of improving patient compliance. Pulm Med. 2011.

doi: https://doi.org/10.1155/2011/325362

14. Centers for Medicaid and Medicare (CMS). Home oxygen therapy. CMS website. https://www.cms.gov/Outreach-andEducation/Medicare-Learning-Network-MLN/MLNProducts/ Downloads/Home-Oxygen-Therapy-Text-Only.pdf Published October 2016. Accessed October 24, 2016.

15. Sjöberg F, Singer M. The medical use of oxygen: a time for critical reappraisal. J Intern Med. 2013; 274(6):505. doi: https://doi.org/10.1111/joim.12139

16. Feemster LC, Au DH. Penalizing hospitals for chronic obstructive pulmonary disease readmissions. Am J Respir Crit Care Med. 2014; 189(6):634-639.

doi: https://doi.org/10.1164/rccm.201308-1541PP

17. Stein BD, Bautista A, Schumock GT, et al. The validity of International Classification of Diseases, Ninth Revision, Clinical Modification diagnosis codes for identifying patients hospitalized for COPD exacerbations. Chest. 2012; 141(1): 87-93. doi: https://doi.org/10.1378/chest.11-0024

18. Landis R, Koch CG. The measurement of observer agreement for categorical data. Biometrics. 1977; 33(1): 159-174. doi: https://doi.org/10.2307/2529310

19. Long-Term Oxygen Treatment Trial Research Group. A randomized trial of long-term oxygen for COPD with moderate desaturation. N Engl J Med. 2016;375(17):1617-1627. doi: https://doi.org/10.1056/NEJMoa1604344

20. Assimacopoulos EM, Liao J, Heard JP, Kluesner KM, Wilson J, Wibbenmeyer LA. The national incidence and resource utilization of burn injuries sustained while smoking on home oxygen therapy. J Burn Care Res. 2016;37(1):25-31. doi: https://doi.org/10.1097/BCR.0000000000000291

21. Wolff KB, Soncrant C, Mills PD, Hemphill RR. Flash burns while on home oxygen therapy tracking trends and identifying areas for improvement. Am J Med Qual. 2016; 32(4): 445-452. doi: https://doi.org/10.1177/1062860616658343

22. Shah T, Press VG, Huisingh-Scheetz M, White SR. COPD readmissions: addressing COPD in the era of value-based healthcare. Chest. 2016; 50(4):916-926. doi: https://doi.org/10.1016/j.chest.2016.05.002

23. Cabana MD, Rand CS, Powe NR, et al. Why don't physicians follow clinical practice guidelines? A framework for improvement. JAMA. 1999; 282(15):1458-1465.

doi: https://doi.org/10.1001/jama.282.15.1458 
24.

Agency for Healthcare Research and Quality/ Patient Safety Network. Patient Safety Primer: Medication reconciliation. Patient Safety Network website. https://psnet.ahrq.gov/primers/ 25. primer/1/medication-reconciliation Accessed October 24, 2016.

Boockvar KS, Carlson LaCorte H, Giambanco V, et al. Medication reconciliation for reducing drug-discrepancy adverse events. Am J Geriatr Pharmacother. 2006; 4(3):236.

doi: https://doi.org/10.1016/j.amjopharm.2006.09.003

26.

Mueller SK, Sponsler KC, Kripalani S, Schnipper JL. Hospitalbased medication reconciliation practices: a systematic review. Arch Intern Med. 2012; 172:1057. doi: https://doi.org/10.1001/archinternmed.2012.2246

27.

Agency for Healthcare Research and Quality. Medications at transitions and clinical handoffs (MATCH) toolkit for medications reconciliation, Chapter 3: Developing change: Designing the medication reconciliation process. http://www. ahrq.gov/professionals/quality-patient-safety/patient-safetyresources/resources/match/match3.html Published August 2012. Accessed October 24, 2016. 